\title{
Public Expectations of Social Media Use by Critical Infrastructure Operators During Crises: Lessons Learned from France
}

\author{
Laura Petersen $^{1}$, Laure Fallou ${ }^{1}$, Paul Reilly $^{2}$, and Elisa Serafinelli ${ }^{2}$ \\ ${ }^{1}$ European-Mediterranean Seismological Centre (EMSC), c/o CEA, Bât. BARD, Centre DAM \\ - Ile de France, 91297, Arpajon, France \\ petersendemsc-csem.org \\ 2 University of Sheffield, 211 Portobello Rd, S1 4DP, Sheffield, UK \\ $\{\mathrm{p} \cdot j \cdot r e i l l y$, e.serafinelli\}@sheffield.ac.uk
}

\begin{abstract}
Previous research into the role of social media in crisis communication has tended to overlook how critical infrastructure (CI) operators might benefit from sites such as Facebook and Twitter, focusing instead on how emergency managers and the general public use such platforms. This paper sets out to address this gap by empirically exploring the expectations of French citizens in relation to the crisis communication strategies deployed by CI operators during major incidents. It does so by reviewing the literature on crisis communication, presenting the results of an online questionnaire, and comparing these results to the current practices of the A31 Highway in France, which were examined via a semi-structured interview. Results indicate that members of the public expect CI operators to communicate via traditional and social media. Therefore, the paper proposes that A31 Highway operators should expand their current practices to include social media.
\end{abstract}

Keywords: Social media, crisis communication, critical infrastructure operators.

\section{Introduction}

Crisis communication can be defined as "the provision of effective and efficient messages to relevant audiences during the course of a crisis process" [1]. Social media has been identified as an increasingly important source of information during crisis situations [2]. Previous research in this area has tended to focus on how emergency response personnel or citizens use social media during such incidents [3 - 7], overlooking its benefits for other key stakeholders such as critical infrastructure (CI) operators. As such, there remains relatively little empirical research exploring public expectations of information provided by CI operators during crisis situations. The EU Horizon 2020 project IMPROVER (Improved risk evaluation and implementation of resilience con- 
cepts to critical infrastructure), makes use of Living Labs, or clustered regions of different types of infrastructure which provide specific services to a city or region. One such Living Lab is the A31 Highway in France. This paper will addresses these underresearched issues by presenting a succinct literature review on public expectations of disaster related information shared via social media. It then describes the French A31 Highway case study. After, the methodology of the online questionnaire and interviewbased study of the A31 French Living Lab are described. This is followed by a presentation of the questionnaire and interview results, accompanied by a comprehensive discussion on the subject and a conclusion.

\section{General expectations of social media use in crisis}

The public expect to be able to find information relating to disasters from both traditional and social media sources; recent research suggests that people use a combination of these sources to find information during disasters [6 - 9]. For example, both Facebook and Twitter were heavily used by German citizens to find information during 2013 European Floods [10]. One reason people turn towards social media is for its perceived efficacy in locating real-time information. During the 2011 Great East Japan Earthquake, a main reason that people turned to social media was the ease with which they could search for and obtain information [11]. Furthermore, a survey conducted in Europe by Reuter and Spielhofer (2016) found that $77 \%$ of respondents felt that information was made available faster during emergencies on social media than on traditional media [3]. The same Reuter and Spielhofer survey found that $43 \%$ of respondents have already looked for crisis information on social media, with $70 \%$ of those having looked for road or traffic conditions [3]. A study investigating Twitter data corresponding to 26 crises between 2012 and 2013 found that while on average $7 \%$ of tweets contained information related to infrastructure and utilities, these tweets were among the most retweeted during such incidents [12]. Therefore it appears that information related to $\mathrm{CI}$ is of great interest to the public in times of crisis. There is also evidence that the public turn to the social media accounts of emergency responders during crisis situations and studies show that the public also expect responses from emergency services to their questions and comments posted on these platforms [3, 6 - 7]. As previously stated, less is known about public expectations of social media use by CI operators. Clearly, citizens appear to expect updates from CI operators about service restoration [2]. Reuter (2015) examined public information needs from energy operators during a blackout and found that both the duration and cause were of key interest [13]. Some operators are already using social media to meet these information needs [2].

\section{Background on French A31 Highway case study}

The French A31 Highway, also known by 'E25' in the European code, is an essential transport infrastructure network at a transnational scale. The section Nancy-Metz-Luxemburg is studied within the IMPROVER project. Its traffic is one of the most significant in France with 100,000 vehicles per day. The A31 Highway is used for intercity 
travel by the approximately 1,500,000 inhabitants of the Moselle valley and is also used by the numerous heavy goods vehicles from or to Luxemburg, Belgium, the Netherlands and Northern Germany. Significant traffic peaks can occur during holiday periods as it is used by Dutch, Belgian, German and French travelers. The traffic often reaches close to saturation conditions and traffic jams are observed daily from 15:00 to 20:00 in the section that connects Luxembourg to France and at the junction with A33 towards or from Metz. The studied infrastructure is managed by DIR Est (Direction Interdépartementale des Routes de l'Est - Eastern Interdepartmental Road Office), a decentralized service of French Ministry of Ecology which deals with the maintenance and the exploitation of public roads networks. In order to develop a policy regarding risk management, this service collaborates with the DDT57 (Direction départementales des Territoires de Moselle - Departmental Office of the Moselle Territories), another decentralized service of France, which deals with the sustainable development of territories, natural hazard prevention, implementation of regional planning politics and building permits. DIR Est also collaborates with other private roads exploitation companies (SANEF), regional authorities (DREAL), municipalities, dependent industries etc. in the event of a crisis. DIR Est and DDT57 are associated partners of the IMPROVER project. [14]

\section{$4 \quad$ Methodology}

\subsection{Research Questions}

Specifically, two Research Questions emerged from the literature reviewed above:

1. What do French citizens expect of CI operators in regards to information provision during crisis situations?

2. How do these declared expectations compare to the current communication efforts of the French A31 Highway Living Lab?

An online questionnaire and interview-based study was designed to investigate these questions. Ethics approval was sought and obtained from the respective authorities prior to data being collected.

\subsection{Questionnaire}

The target population for the questionnaire was French citizens aged 18 years and over. In order to maximize the response rate, the questionnaire was translated into French and also made available in English. Convenience sampling was used for the questionnaire. It was structured as follows: First, a brief description of the project was provided and participants were informed of their right to withdraw from the project at any time, as well as how all data would be handled during the project. For the purposes of this questionnaire, respondents were presented with the following definition of a disaster: "an event which has catastrophic consequences and significantly affects the quality, quantity, or availability of the service provided by the infrastructure." Second, a Likert scale was used to measure participants' expectations. Participants were asked two questions regarding information provision. The first asked, "During and immediately after 
a disaster, I expect critical infrastructure operators to provide me with information..." and presented four scenarios: via calling their telephone number, on their website, on their social media site and through traditional media e.g. interviews with television networks or the radio, press releases. The second proposition asked, "During and immediately after a disaster, I expect critical infrastructure operators to respond to my questions and comments on their social media sites e.g. Twitter." The questionnaire also asked about the participants' demographics and social media habits. Data from the questionnaire was collected between 28 March 2016 and 30 April 2016. The questionnaires were translated back into English at the data entry stage. The questionnaire was disseminated through the IMPROVER consortium partners' contacts as well as through the Living Lab.

\section{Sample characteristics}

A total of 67 participants from France completed the online questionnaire. Due to the dissemination method, this self-selected sample was not broadly representative of the French population. Sample characteristics showed that $58 \%$ of the respondents were men, $40 \%$ were women, and one respondent chose not to answer that question. For comparison, in France $48 \%$ of the population are men and 52\% are women [15]. Most respondents were highly educated with $88 \%$ of them having a university degree or higher, whereas only $33.5 \%$ of the French population have a university level education [16]. Both young and old people appeared to be underrepresented in the study. Respondents aged 18-24 accounted for only $2 \%$ of the total sample (for comparison, French 18-24 year olds make up 8\%), with $0.5 \%$ identifying themselves as aged 55 years and older (for France, $32 \%$ of the population is 65 years or older) [15]. Lastly, $91 \%$ of respondents have an account with a social media site such as Facebook or Twitter. For comparison, in France, $83 \%$ of households have Internet access and $85 \%$ of individuals have used Internet in the last three months [17]. When asked an open-ended question to list up to three social media sites the respondent used most, $81 \%$ listed Facebook and $18 \%$ or less listed other popular platforms (Figure 1).

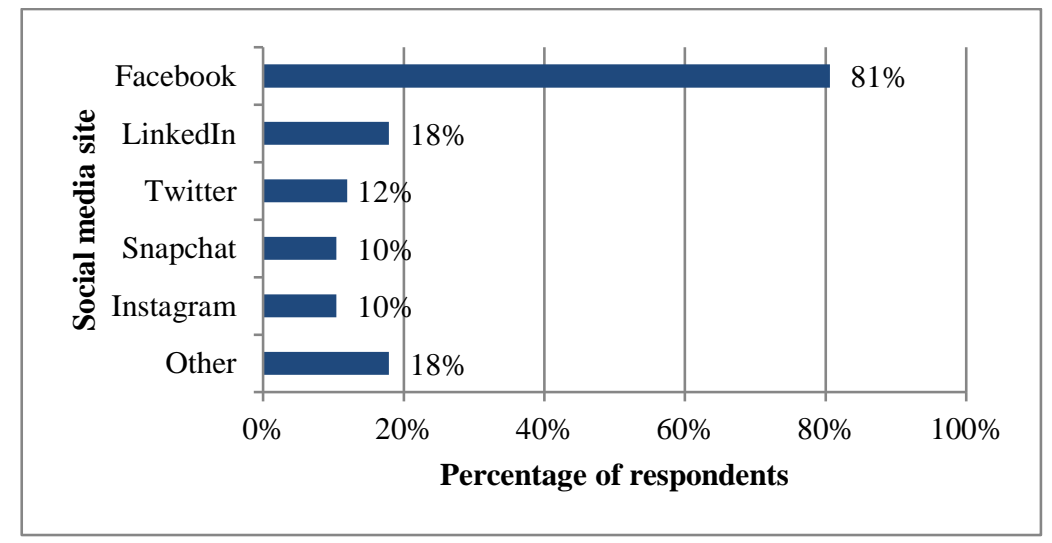

Fig. 1. Respondent's most frequently used social media sites (list up to three). 


\subsection{Interview}

The findings were then compared to the current practices of the French A31 Highway. Two in-person, group interviews took place with actors from the Living Lab, one comprising of actors from DIR Est and another from DDT57. These included representatives from the office dealing with the intersection of the A31 between Nancy and Luxembourg, the office in charge of real time management for crisis interventions, the crisis management and alternative route designation office, and the urbanism and risk prevention office. Interviews were held in French and then data was translated into English for analysis. Data from the interview was collected on 25-26 May 2016.

\section{Questionnaire results}

\subsection{Expectations for information to be provided on social media}

When asked if respondents expected CI operators to provide disaster related information on social media, 79\% strongly agreed or agreed (Figure 2). Few respondents $(16 \%)$ were unsure or neutral in regards to the use of social media by CI operators to push disaster related information to the public.

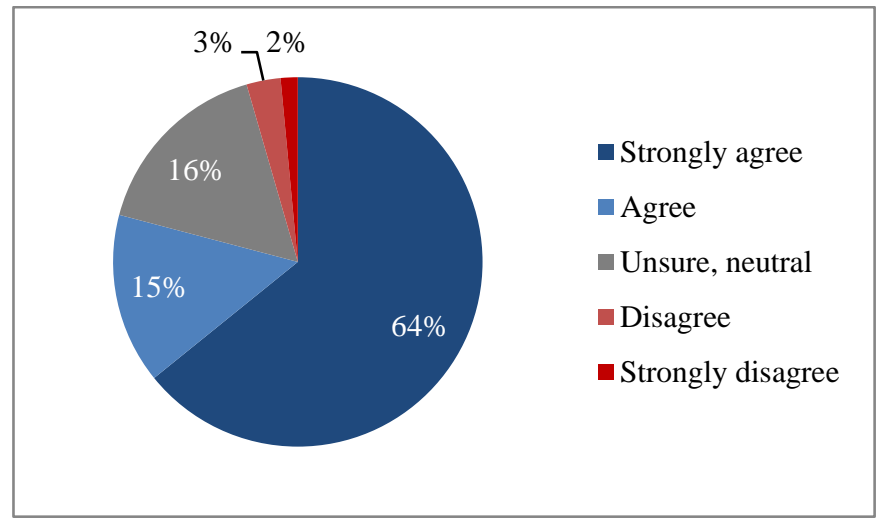

Fig. 2. Expectations that crisis information should be provided via social media

\subsection{Expectations for information to be provided via other channels}

CI operators were expected to use traditional broadcast media such as newspapers, radio or television to communicate with members of the public during such incidents, with $99 \%$ of respondents having strongly agreed or agreed with this statement (Figure 3 ). No respondents disagreed or strongly disagreed with this statement, and only $1 \%$ declared that they were unsure or neutral. The majority of respondents also had high expectations in relation to the availability of crisis information on the website of operators, with $94 \%$ having agreed or strongly agreed (Figure 4 ). Only $4 \%$ of respondents 
were unsure or neutral. When asked if respondents expected operators to provide information via calling a telephone number, $67 \%$ agreed or strongly agreed (Figure 5). 24\% of respondents were unsure or neutral in regards to CI operators having a telephone hotline to make disaster related information available to the public.

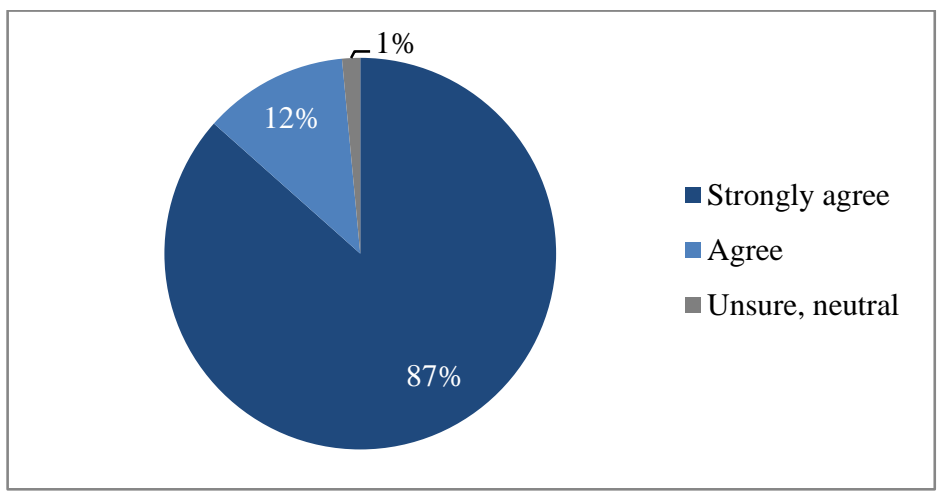

Fig. 3. Expectations that crisis information should be provided via traditional media

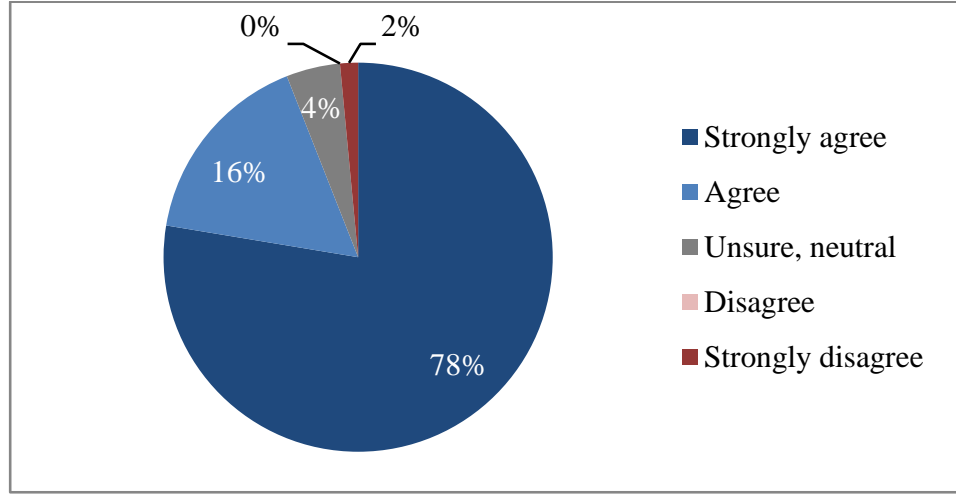

Fig. 4. Expectations that crisis information should be provided via websites

\subsection{Expectations for two way communication on social media}

When asked if they expect CI operators to respond to comments sent by members of the public to their social media accounts, $61 \%$ of respondents agreed or strongly agreed (Figure 7$)$. There was high uncertainty/neutrality $(26 \%)$ in regards to responding to queries, and a large portion of respondents selected disagree and strongly disagree (13\%). Lastly, $77 \%$ of respondents who expected CI operators to communicate via social media also expected them to respond to questions or comments. 


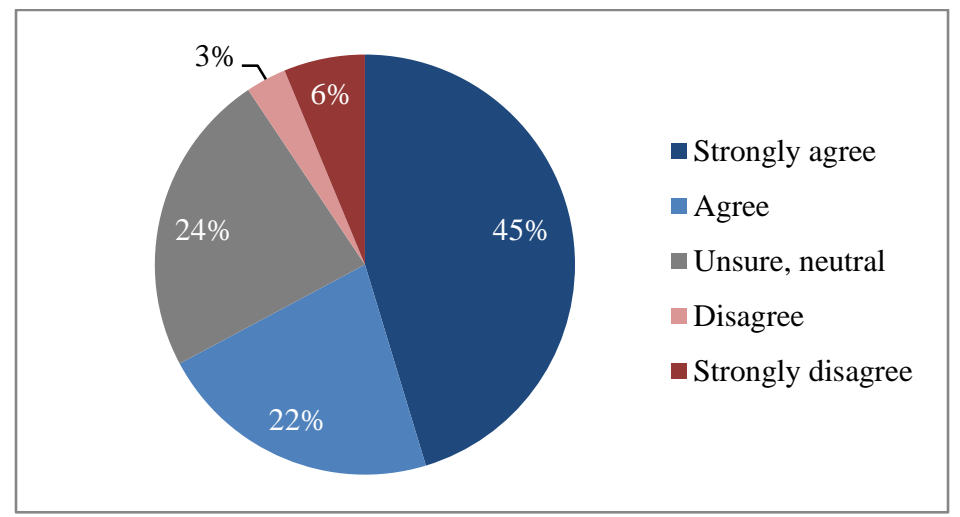

Fig. 5. Expectations that crisis information should be provided via calling a telephone number

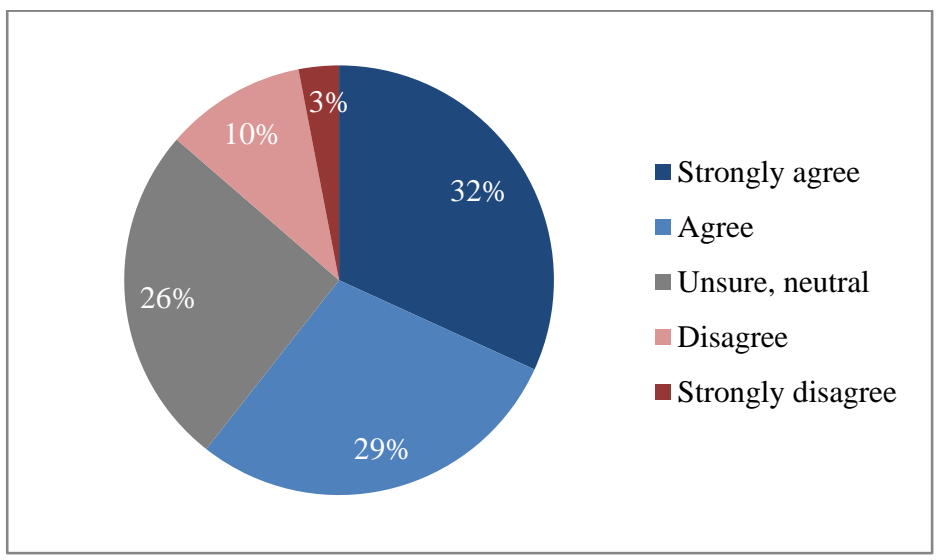

Fig. 6. Respondents' expectations for two way communication on social media during and after a disaster

\section{$6 \quad$ Interview results}

French A31 Highway operators identified two different types of general public who use their infrastructure: individual users and professional users (truck drivers). However their communication intended for users of the infrastructure is not dependent on which type of user they are addressing. The DIR Est is charged with communicating with the public. Since they are a public institution, they "must guarantee the reliability, usefulness, and credibility of information" before they share it with the public (Interviewee 1). DDT57 gather and synthesize data to be shared with the crisis cell and with the Préfet in times of crisis and do not communicate with the public. The emergency response structure in France is such that the Préfet is the one who makes all the crisis management decisions, including those related to communication. As such, the 
DIR Est follows the guidelines and regulations in regards to crisis communication, waiting for approval from the appropriate persons before sharing information with the public.

They find when it comes to their crisis communication, two elements are absolutely necessary to convey to the public: 1) delays associated with the crisis and 2) the cause of the crisis. Furthermore, the information must be updated regularly in accordance with which crisis management stage they are in and the ever evolving traffic conditions. According to our interviewees, "users demand to be informed of the situation" (Interviewee 1). They have learned from past mistakes where they did not inform the public of the situation, such as the example shared in this anecdote:

"In 2013, part of the highway was stuck in a standstill traffic jam. Some people began to turn around and go the wrong way on the motorway! This was happening around the same time that the highway was starting to circulate again, and so going the wrong way was risking a major accident. If the users had been provided the information related to the traffic jam, this crisis could have been prevented" (Interviewee 2).

A strategy focusing on communication with their users exists and is applicable in both normal times and crisis times. Crisis communication involves more frequent communication and requires a greater mobilization of actors than day-to-day communication. In general, they distinguish between two types of communication: programmed (when the event can be anticipated, such as certain weather related events or foreseen traffic peaks, for example during holiday periods) and real time (when the event cannot be anticipated). Programmed communication uses three main channels: traditional media (via the press), the DIR Est website, as well as collaborating to put the information on Bison Futé, the official French government website relating to traffic conditions. They may also implement warning levels when appropriate. For real time communication, they have a partnership with the radio station France Bleu, which allows them to not only disseminate traffic information at scheduled times, but also in the form of "flash" information, whereby the regular programming is interrupted in order to warn the listeners/highway users. "These information 'flashes' are sometimes picked up by other radio stations," said one operator (Interviewee 3), "but we do not have partnerships with other stations." Lastly, they communicate via VMS (variable messaging signs - electric traffic signs used on road ways to convey relevant information), which "allow us to communicate as closely as possible to 'in real time' when an incident occurs" (Interviewee 3). During crisis times, the press takes on an even greater role in information sharing. The DIR Est inform not only the radio but also television news channels and online news sites about sudden onset crisis events. They see their job as provider of critical, crisis-related information to the press, and the job of the press as messenger of said information to the public.

The radio and the VMS are seen by the operators to be the most effective means of communicating with the public. The VMS are especially effective as they are seen by the current users and can be implemented very close to a given incident. The radio station France Bleu is listened to by many of the highway users, and in the case of an incident, operators from DIR Est said that users already know to turn on that station to find out more information. Concerning the radio, however, DDT57 brought up a limitation. "The problem with the A31 is that there is no dedicated radio station and the 
promotion of the partnership with France Bleu does not have as great an impact as a dedicated radio station would" (Interviewee 4).

They do not send out SMS warnings, nor do they use social media, as they believe their current strategy has "already proved its effectiveness" (Interviewee 1). They are aware that users may communicate information via social media, but they see this kind of information as being the subjective opinion of a given user and as such don't view social media as a reliable information source. They did mention that Loractu and ITLF (Info Traffic Lorraine et Frontière), two local news sources, are active on social media and discuss traffic conditions. However, there is no official partnership with them.

\section{Discussion}

\subsection{High expectations for information to be available on social and traditional media channels}

Results indicate that members of the public expect CI operators to provide disaster related information via both traditional and social media. Overall, expectations were high for all four channels studied. There was no disagreement among respondents when it came to expecting disaster related information relevant to CI to be available through traditional means such as radio or television. This further reinforces the idea that even to the public, digital media such as websites or social media platforms is meant to compliment more traditional crisis communication methods and not replace them. CI operator run websites should then be used as another channel for information dissemination, as $94 \%$ of respondents expected it. Respondents also have high expectations for information to be available on social media (79\%) and as such social media should be included in crisis communication plans as well. High expectations for information to be available on the Internet via social media and websites demonstrate high expectations for operators to be proactive in pushing information to citizens. This is furthered by the high uncertainty/neutrality (24\%) for there to be a telephone hotline available, which would consist of the respondent being proactive in searching for the information. Furthermore, this substantiates the importance of understanding the technological culture of the local population when putting into place crisis communication plans [18].

The majority of respondents expected operators to respond to queries, confirming the importance of two-way communication. However, the high amount of disagreement with this statement furthers the idea that pushing information to citizens should be more of a priority for operators than responding to queries. Respondents who expected CI operators to communicate via social media also had high expectations for a response. This can be explained by the fact that people tend to use the media platforms that they are already familiar with during crisis $[19,20]$. High expectations for a response from operators further reflects the fact that social media generally encourages interaction and dialogue between users as it is an information space devoid of hierarchy [21]. 


\subsection{Expectations for social media use are not currently being met by the operator}

The current public communication efforts of the operators at the A31 Highway appear to meet public expectations when it comes to using traditional media and website channels. They currently have partnerships with various members of traditional media, from print media to radio and online news. The importance in using traditional media as a means for crisis communication is acknowledged by the operators. The A31 Highway also publishes crisis related information on their website.

However, as they do not have social media accounts, they are not yet meeting this expectation. It is important however to keep in mind that this expectation may be an uninformed one as the IMPROVER questionnaire did not establish what the participants understood as crisis-related information on social media. Limitations with the use of social media include those laid out by the operators, namely reliability of information and the need to verify it. Despite this, the fact that respondents have high expectations for operators to use social media clearly indicates that this is an area where the operators can improve the effectiveness of their crisis communication. While the operators stated that they felt their crisis communication to already be efficient, respondents clearly demonstrate a desire for information to be shared on social media, indicating either that participants didn't understand the implications of using social media for crisis communication or a gap in perception of the crisis communication plan. As an institution of the French government, the A31 Highway operators must follow a hierarchical communication strategy, which is indeed the opposite of the information flows on social media. The A31 Highway appears to still be in a top-down approach, insisting on controlling information. The importance of providing verified information is also cited as a reason for not using social media. However, once verified, other institutions in the French government do communicate crisis information via social media (the Ministry of Interior for example). While the information in this case is indeed published less rapidly than that coming from ordinary users, it is still important to be able to find official information sources on social media. As the A31 Highway already provides verified, official messages in "near real time" on their VMS system, these messages could potentially be re-employed on social media. Indeed, multi-channel crisis communication is more effective $[22,23]$. If the reason for not using social media is to avoid having to deal with queries that might be generated on such platforms, a transparent no response policy could help operators to meet citizens' expectations for information to be pushed via this channel, which were higher than expectations for queries to be answered, and continue with the current, top-down communication strategy.

Another solution to meeting social media expectations could be partnerships. As they already work in partnership with traditional media generally when it comes to public communication, it may be interesting to see if these actors' social media sites would be considered by the public as an appropriate source to find CI related disaster information. Perhaps an official partnership with either Loractu or ITLF could be envisioned, similar to the current partnership with Radio Bleu. As such, this approach could be another dimension of their existing relationships with news media. While the expectations studied here were for CI operators to provide the information directly, it may suffice to simply inform the public that crisis information related to the A31 Highway 
is available on social media at a partner's account in an official capacity. Further research should look into this. However, the comment on the limitations of using a partner radio station instead of a dedicated radio station during the interview also merits further investigation before putting into place more such partnerships, especially considering the results of the questionnaire, which asked about social media use by CI operators themselves.

The A31 Highway does not currently use information found on social media as they do not trust user provided information nor do they perceive it to be useful. Currently, social media is used by many different emergency response organisations to improve situational awareness. Indeed, social media monitoring leads to better situational awareness as it provides eye witnesses accounts. However, as expectations related to this were not asked of respondents, further research is needed to see if this is indeed an area that the public expect CI operators to further develop. In conclusion, it is suggested then that the operators expand their crisis communication strategy to include social media.

\subsection{Limitations}

The methods elaborated above have a number of limitations that should be acknowledged. As discussed earlier, the self-selecting sample engaged in the online questionnaire did not adequately represent the demographics of France. It should also be noted that the use of the website to distribute the questionnaire was likely to have skewed the sample in favor of those who used the Internet and social media on a regular basis.

\section{Conclusions}

Our findings suggest that CI operators should continue to use traditional media during crisis situations, and that this should be supplemented through the provision of disaster related information via the Internet, with websites and social media platforms maintained by CI operators. The French A31 Highway should expand their crisis communication efforts to include social media in order to meet public expectations. This may be difficult to put into place due to the current organisational culture which views social media poorly. Despite this, high expectations for information to be pushed via social media demonstrate the importance in including it in a multichannel crisis communication strategy. However, it should be acknowledged that this was a self-selecting sample that was not representative of the demographics in the population studied, and as it was an online questionnaire it most likely attracted people who generally use the Internet and social media. Further work is needed to explore the perspectives of citizens who are unable or unwilling to use digital media. A future questionnaire is being developed within the IMPROVER project to better understand these expectations. Lastly, the IMPROVER project is also currently working on the development of a communication strategy for CI operators to deploy during each stage of a crisis that will encompass both digital and traditional media platforms. 


\section{References}

1. Freberg, K., Saling, K., Vidoloff, K. G., Eosco, G.: Using value modelling to evaluate social media messages: The case of Hurricane Irene. Public Relations Review, 39, 185-192 (2013).

2. Petersen, L., Fallou, L., Reilly, P., Serafinelli, E.: Public expectations of social media use by critical infrastructure operators in crisis communication. In: 14th ISCRAM International Conference on Information Systems for Crisis Response and Management Conference on Agility is Coming, IMT Mines Albi-Carmaux (École Mines-Télécom), Albi, France (2017).

3. Reuter, C., Spielhofer, T.: Towards social resilience: A quantitative and qualitative survey on citizens' perception of social media in emergencies in Europe. Technological Forecasting \& Social Change. (2016). http://dx.doi.org/10.1016/j.techfore.2016.07.038

4. Reuter,C., Ludwig, T., Kaufold, M., Spielhofer, T.: Emergency services' attitudes towards social media: A quantitative and qualitative survey across Europe. International Journal of Human-Computer Studies. (2016). http://dx.doi.org/10.1016/j.ijhcs.2016.03.005i

5. Bruns, A., Burgess, J., Crawford, K., \& Shaw, F.: \# qldfloods and @ QPSMedia : Crisis Communication on Twitter in the 2011 South East Queensland Floods. Brisbane: ARC Centre of Excellence for Creative Industries and Innovation. (2012).

6. The American Red Cross: Web Users Increasingly Rely on Social Media to Seek Help in a Disaster, Press Release. (2009). In: Lindsay, B. R. Social Media and Disasters: Current Uses, Future Options, and Policy Considerations. Congressional Research Service. (2011).

7. Lindsay, B.R.: Social Media and Disasters: Current Uses, Future Options, and Policy Considerations. CRS Report for Congress. (2011). https://www.fas.org/sgp/crs/homesec/R41987.pdf

8. Burger, J, Gochfeld, M, Jeitner, C, Pittfield, T, Donio, M.: Trusted information sources used during and after Superstorm Sandy: TV and radio were used more often than social media, Journal of Toxicology and Environmental Health, 76:20:1138-1150 (2013).

9. Mitomo, H.; Otsuka, T.; Jeon, S.Y.; Cheng W.: The role of ICT and mass media in postdisaster restoration and recovery progress: A case of the Great East Japan Earthquake, 24th European Regional Conference of the International Telecommunication Society, Florence, Italy, 20-23 October 2013, (2013).

10. Kaufhold, M., Reuter, C.: The Self-Organization of Digital Volunteers across Social Media: The Case of the 2013 European Floods in Germany. Homeland Security \& Emergency Management, (2016). DOI: 10.1515/jhsem-2015-0063

11. Takeuchi, Y., Peary, B. D.., Shaw, R.: Utilization of Social Media in the East Japan Earthquake and Tsunami and its Effectiveness. Jsnds.Org, 34(1), 3-18, (2012).

12. Olteanu, A., Vieweg, S., \& Castillo, C.: What to Expect When the Unexpected Happens: Social Media Communications Across Crises. CSCW '15, March 14 - 18 2015, Vancouver, BC, Canada, ACM 978-1-4503-2922-4/15/03 (2015). DOI: 10.1145/2675133.2675242

13. Reuter, C.: Communication between Power Blackout and Mobile Network Overload. International Journal of Information Systems for Crisis Response and Management, 6(2), 38-53, (2015). DOI: 10.4018/ijiscram.2014040103

14. Ioannou, I., Aspinall, W., Bouffier, C., Carreira, E., Honfi, D., Lange, D., Melkunaite, L., Kristine Reitan, N., Rossetto, T., Storesund, K., Teixeira, R.: IMPROVER Deliverable 2.1 Methodology for identifying hazard scenarios to assess the resilience of critical infrastructure. (2016)

15. INSEE (Institut national de la statistique et des études économiques): Population totale par sexe et âge au 1er janvier 2017, France, (2017), https://www.insee.fr/fr/statistiques $/ 1892086$ ? sommaire $=1912926$ 
16. OECD Data.: Adult education level (indicator). (2017). DOI: $10.1787 / 36 b c e 3 f e-e n, a c-$ cessed 15 June 2017

17. Eurostat: Digital economy and society statistics - households and individuals. (2015). http://ec.europa.eu/eurostat/statistics-explained/index.php/Information_society_statistics__households_and_individuals, accessed 20 April 2016.

18. Fallou, F.: Culture and Risk management in Man-made and Natural Disasters. EU H2020 Project CARISMAND. (2017).

19. Fire Services Commissioner Victoria: Information Interoperability Blueprint. (2013). http://fire-com-live-wp.s3.amazonaws.com/wp-content/uploads/Information-Interoperability-Blueprint.pdf

20. Steelman, T. A., McCaffrey, S. M., Velez, A. L. K., Briefel, J. A.: What information do people use, trust, and find useful during a disaster? Evidence from five large wildfires. Natural Hazards, 76(1), 615-634. (2014). http://doi.org/10.1007/s11069-014-1512-x

21. Giroux, J., Roth, F., \& Herzog, M. Using ICS \& Social Media in Disasters: Opportunities \& Risks for Government. Center for Cecurity Studies/ETH Zurich. P. 5. (2013).

22. Tierney, KJ.: Disaster Response: Research Findings and Their Implications for Resilience Measures. CARRI Research Report 6. (2009). http://www.resilientus.org/wp-content/uploads/2013/06/Tierney-20092.pdf.

23. Stephens, K. K., Barrett, A. K., Mahometa, M. J.: Organizational Communication in Emergencies: Using Multiple Channels and Sources to Combat Noise and Capture Attention. Human Communication Research, 39(2), 230-251. (2013). DOI:10.1111/hcre.12002 